\title{
Implementation of TAM (Technology Acceptance Model) in Project Based Organizations
}

\author{
Amina Binat-i-Yousaf * \\ Capital University of Science \& Technology, Islamabad, Pakistan
}

\begin{abstract}
This study examines the relationship between perceived usefulness of technology and ease of use with technology usage. Data were collected by 100 respondents of government sector of Pakistan. The results show the positive relation between perceived usefulness of technology and ease of use with technology usage with the mediating role of intention to use technology. This study also has theoretical and practical implication in the context of Pakistani organization having projects, as discussed later in the study.
\end{abstract}

\section{Introduction}

Before the start of Technology acceptance model there were many studies related to the use of information system in projects to make them more effective and efficient. Many people do not consider it as more effective way towards the success of project as compared to the human factor. Since seventies, researchers have been trying to study the usefulness and effectiveness of the information systems. Bagozzi et al. (1992) has done research to prove theoretical model of effectiveness and usefulness of computer-based information system practically.

Technology acceptance model was suggested by Mayer et al. (1995), and it has been used by number of researchers in their studies. Technology acceptance model is the model that basically relates the perceived usefulness and ease of use of technology in projects. This model is formed to develop awareness in the people related to the use of information systems.

Venkatesh and Davis (2000), found the effectiveness and usefulness of technology acceptance model. They explored ease of use and perceived usefulness of technology acceptance model. They did practical research on 4 project base organization and based on organizational data, they concluded that use of information system improves the effectiveness and usefulness of the organizations or the projects. Similarly, Legris et al. (2003) found that the technology acceptance model is a useful model in order to understand the effectiveness of information system in project based organizations. Technology acceptance model is tested along with many different tools and other models, but still this model remains successful model as compared

*Corresponding author.

Email: aminabintiyousaf@gmail.com to the other models.

Recent studies further related technology acceptance model to explain the influence of acceptance of other Google applications. Cheung and Vogel (2013), found the effect of collaborative learning of the students. They collected data from 136 students who were enrolled in the master degree program and asked them regarding the usage of information systems and the group work in either project based organizations or group work of the students. Wallace and Sheetz (2014), found the importance of software measures in project management. They conducted the test to prove the importance of use of software in project based organizations or in projects. Their study was based on technology acceptance model and the construction of software on the desirable properties of software.

Furthermore, Toft et al. (2014) posited that one type of system is not enough for all types of work, and similar system can work efficiently and effectively for years. They suggested that each system should form according to the need of project or organization. Similarly, systems must be updated with the passage of time. Zheng (2016) found technology acceptance model to be a problem solving model for promoting mobile donations for non-profit organizations. Costa et al. (2016), found that it very difficult to use these systems in project based organizations, so their basic research is on the adoption and satisfaction of the people for using these systems. Hwang et al. (2017), in their study also suggested the moderating role of intention to use technology in project based organizations. Using technology in project based organizations is not a very common practice. It influences not only organizations processes and strategy but also the projects.

There is huge gap in project based organizations re- 
lated to the use of technology, especially in Pakistani context. A lot of work is needed to be done now as many organizations have shifted their projects based on technology. The purpose of this study is to increase the use of awareness related to the use of technology in project based organizations, especially in Pakistan. Organizations and project managers will able to enhance projects success rates. It is assumed that study will help many organizations in Pakistan, to learn the importance of technology and its impact on project success by using technology in project based organizations. As it is mentioned above that technology usage has now been considered as the critical success factor for project success and definitely it will also increase the success rate of projects in Pakistan.

\section{Literature Review}

\subsection{Relationship of perceived usefulness of technology with technology usage}

A lot of research has been done previously to understand the usefulness of technology through which it influences the technology usage, like e-tourism is gaining popularity, enhancing the technology usage (Ukpabi and Karjaluoto, 2016). Building information modeling is used to change the construction industry with the extension of theory of acceptance and use technology to increase the use of information technology in construction industry (Howard et al., 2017). The unified theory of acceptance has been used widely in the area of information technology to insure the acceptance of technology usage in different areas (Venkatesh et al., 2016).

The study extends the unified theory of acceptance to find out the use of technology in different areas like the use of technology of social media such as Instagram. In this theory, they studied the use of technology for using social media (Järvinen et al., 2016). This paper focused on digital sakuga means digital drawing. Means they want to increase the use of technology even in the area of arts, which allows the individuals, related to the field of art, to adopt information technology (ICHIKOHJI, 2016). Another study by Cai et al. (2017) explored the major reasons why there is a gender difference while using information technology. They tried to see the difference in the use of information technology in different areas of the world to understand why there is a difference between the use of technology in different areas (Rojas-Méndez et al., 2017). Massive open online courses increased the trend for learning online courses, which means increase in trend for using information system at student life (Ouyang et al., 2017). Another study explored the behavior of students as to why the trend of using technology increased, what are the main reasons for the increase in usage (Padilla-
MeléNdez et al., 2013).

Based on the above literature, following hypothesis has been developed:

H1. Perceived usefulness of technology is positively related to technology usage

\subsection{Relationship of ease of use with tech- nology usage}

Ample literature provides evidence that why there are still limitations in applying the wide range of analysis in human neurosciences, because there is less ease of use in using information technology (Gorgolewski et al., 2017). Literature tells us how the use of information technology varies in different countries because of the culture and its not as easy to use in every area because of the culture at that place. Some people dont appreciate their children to use technology (Hallikainen et al., 2017). Wu and Chen (2017) posited that increase in the ease of use of information technology so that massive open online courses will be able to help and teach a lot of students in those areas who cant afford study in expensive universities. Massive open online courses increased the trend for learning online courses, which means increase in trend for using information system at student life (Ouyang et al., 2017).

Another study conducted to see how banks and financial service providers are delivering their finances through e-banking, because of the ease of use of technology (Wang et al., 2017). Padilla-MeléNdez et al. (2013) studied the behavior of students that why the trend of using information technology increase, what are the main reasons for the increase in usage. The use of technology in medical field is considered easy so that the people who take care of patients other than doctors can also easily operate the systems (Wouters et al., 2017). Gender difference in playfulness of technology acceptance model has also been explored by researchers. The model checks what are the main reasons in order to remove this gender barrier? (PadillaMeléNdez et al., 2013). Similarly, another study posited the advantages of acceptance of wireless internet via information technology and how it is easy to use information systems (Lu et al., 2003).

\section{H2. Ease of use is positively related to technology usage}

\subsection{Relationship of intention to use tech- nology with technology usage}

Researchers have studied the advantages of acceptance of wireless internet via information technology and how it is easy to use information systems ( $\mathrm{Lu}$ et al., 2003). Massive open online courses increase the 
trend for learning online courses, which means increase in trend for using information system at student life (Ouyang et al., 2017). The use of information technology varies in different countries because of the culture and its not as easy to use in every area because of the culture at that place. Some people dont appreciate their children to use technology (Hallikainen et al., 2017).

Gender difference in playfulness of technology acceptance model has also been explored in order to check how can gender barriers in this regard be removed (Padilla-MeléNdez et al., 2013). Similarly, literature provides evidence on how banks and financial service providers are delivering their finances through e-banking, because of the ease of use of information technology (Wang et al., 2017). A study by Wang et al. (2017) highlighted the importance of information technology when you are at the journey and the people intentionally use information technology in order to remain in touch with the world.

The theoretical extension of technology acceptance model and intention to use technology was also studied in order to check the social influence and instrumental process (Venkatesh et al., 2016). Similarly, research elaborates the use of intention to the looks that how a website looks like will attract more people towards it and make more intention to use technology (Al-Qeisi et al., 2014). Relating the performance of person with the data analysis, data searching, mining and also the similar things that are if there is a use of information technology then the work will become easy and it will create the intention to work by using technology (Kwon et al., 2014).

H3. Intention to use technology is positively related to technology usage

\subsection{Relationship of perceived usefulness of technology with intention to use tech- nology}

A lot of research has been done previously to understand the usefulness of technology through which it influences the technology usage, like e-tourism is getting famous, leading to the increase in technology usage (Ukpabi and Karjaluoto, 2016). Building information modeling is used to change the construction industry with the extension of theory of acceptance and use technology to increase the use of information technology in construction industry (Howard et al., 2017). A study has been conducted to see the difference in the use of information technology in different areas of the world to understand why there is a difference between the use of technology in different areas (Rojas-Méndez et al., 2017).

Another study tested the theoretical extension of technology acceptance model and intention to use technology in order to check the social influence and in- strumental process (Venkatesh et al., 2016). However, literature explains that the use of information technology varies in different countries because of the culture and its not as easy to use in every area because of the culture at that place. Some people dont appreciate their children to use technology (Hallikainen et al., 2017).

H4. Perceived usefulness of technology is positively related to Intention to use technology

\subsection{Relationship of Ease of use with inten- tion to use technology}

Researchers posited why there are still limitations in applying the wide range of analysis in human neurosciences, because there is less ease of use in using information technology (Gorgolewski et al., 2017). Wu and Chen (2017) conducted a study, aiming to help increase the ease of use of information technology so that massive open online courses will be able to help and teach a lot of students in those areas where they cant afford to study in expensive universities. Moreover, another study explored the major reasons why there is a gender difference while using information technology, trying to resolve the issue by conducting different studies so that people belonging to any gender can use information technology (Cai et al., 2017).

Padilla-MeléNdez et al. (2013) studied the behavior of students regarding the trend of increased usage of information technology and what are the main reasons for the increase in usage. Moreover, use of technology in medical field must be easy so that the people who take care of patients other than doctors can also easily operate the systems (Wouters et al., 2017).

H5. Ease of use is positively related to Intention to use technology

\section{Theoretical framework}

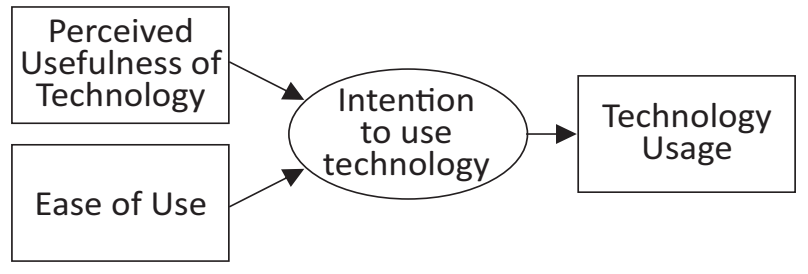

Figure 1: Conceptual Framework

\section{Methodology}

\subsection{Sample and procedures}

For this study, convenient sampling technique was used to examine the impact of perceived usefulness of 
technology and ease of use on technology usage with mediating role of intention to use technology. The sample was selected from government sector of Islamabad (Smart PCB). Smart PCB is multi-disciplinary program agency under the Ministry of Defense Production, Pakistan which is dedicated for evaluation of science and technology for use by the military. For study purpose, 120 questionnaires were distributed among employees, 100 questionnaires were returned back with full response, 10 were incomplete and 10 were not returned back. Additionally, all respondents were assured that their information will be kept only for academic purpose.

\subsection{Measures}

\subsubsection{Perceived usefulness of technology}

Gallivan et al. (2005) used questionnaire of perceived usefulness of technology in their study to measure 5 items of variable. Likert scale was used to measure the level of variable. A sample item was Having a computer available to me would/does improve my productivity. was measured against Strongly Agree (SA), Agree (A), Neutral (N), Disagree (D), and Strongly Disagree (SD). Cronbachs alpha was 0.737.

\subsubsection{Ease of use}

To measure ease of use, a 6 items questionnaire developed by Malhotra and Galletta (2005) was adopted. A sample item was Learning to use [the system] for performance-based activities is easy for me. Strongly Agree (SA), Agree (A), Neutral (N), Disagree (D), and Strongly Disagree (SD). Cronbachs alpha was 0.744.

\subsubsection{Intention to use technology}

Brown et al. (2010) developed questionnaire of Intention to use technology in their study to measure 3 items of variable, which was adopted in order to measure intention to use technology. Likert scale was used to measure the level of variable. A sample item was I intend to use the (collaboration tool) in the next 6 months. Strongly Agree (SA), Agree (A), Neutral (N),
Disagree (D), and Strongly Disagree (SD). Cronbachs alpha was 0.630 .

\subsubsection{Technology usage}

(Chin et al., 2008) used questionnaire of Technology usage in their study to measure 4 items of variable. Likert scale was used to measure the level of variable. A sample item like If the choice of a (technology type) platform were up to me, it would likely be (system). Strongly Agree (SA), Agree (A), Neutral (N), Disagree (D), and Strongly Disagree (SD). Cronbachs alpha was 0.65 .

\section{Results}

Table 1 shows the biveriate correlation result that is significant at $p \leq .01$. Perceived usefulness of technology is correlated with technology usage $(r=.931$, $\mathrm{p}$ $<.01)$, ease of use is correlated with technology usage $(\mathrm{r}=.933, \mathrm{p}<.01)$, and Intention to use technology $(\mathrm{r}$ $=.966, \mathrm{p} \leq .01)$. Technology usage is correlated with Intention to use technology $(\mathrm{r}=.941, \mathrm{p}<.01)$. Ease of use is correlated with intention to use technology ( $r=$ $.991, \mathrm{p}<.01$ ). Respondents were 55 Males and 45 were female and average age of respondents was between 30 35 and average qualification was post graduates.

\subsection{Regression Analysis}

Table 2 shows the results of mediated regression analysis. Respondents completed the questionnaire and regression analysis on Hypothesis 1 shows that PUT is linked with TU and it is accepted as supported by the coefficient regression result $(\mathrm{B}=.837, \mathrm{p}<.01)$. Hypothesis 2 that is EU is linked with TU is also accepted, supported by the coefficient regression results $(\mathrm{B}=.883, \mathrm{p}<.01)$. Hypothesis 3 , mediation is run through Baron and Kenny (1986) four steps. IUT is linked with TU and it is also accepted, supported by the coefficient regression results $(\mathrm{B}=.729, \mathrm{p}<.01)$. Further for hypothesis 4, PUT and IUT is regressed that shows the result $(B=1.049, p<.01)$ then PUT is regressed on

Table 1: Correlation Matrix

\begin{tabular}{llcccccc}
\hline & Variables & Mean & SD & $\mathbf{1}$ & $\mathbf{2}$ & $\mathbf{3}$ & $\mathbf{4}$ \\
\hline 1 & Usefulness of technology & 3.166 & 1.05794 & 1 & & & \\
2 & Ease of use & 2.81 & 0.89016 & $.933^{* *}$ & 1 & & \\
3 & Intention to use & 2.4341 & 1.14915 & $.966^{* *}$ & $.941^{* *}$ & 1 & \\
4 & Tech usage & 2.4341 & 1.05349 & $.955^{* *}$ & $.955^{* *}$ & $.991^{* *}$ & 1 \\
\hline
\end{tabular}

${ }^{* *} p \leq .01$ 
Table 2: Mediated Regression Analysis

\begin{tabular}{|c|c|c|c|c|c|c|}
\hline \multirow{2}{*}{ Predictor } & \multicolumn{3}{|c|}{ Intention to use technology } & \multicolumn{3}{|c|}{ Technology Usage } \\
\hline & $\beta$ & $R^{2}$ & $\Delta R^{2}$ & $\beta$ & $R^{2}$ & $\Delta R^{2}$ \\
\hline \multicolumn{7}{|l|}{ Direct Effects } \\
\hline \multicolumn{7}{|l|}{ Step 1} \\
\hline Control Variables & & & & 0.026 & & \\
\hline \multicolumn{7}{|l|}{ Step 2} \\
\hline Usefulness of tech & $1.049^{* *}$ & 0.931 & 0.931 & $0.837^{* *}$ & 0.871 & 0.869 \\
\hline \multicolumn{7}{|l|}{ Step 3} \\
\hline Ease of use & $1.043^{* *}$ & 0.933 & 0.933 & $0.845^{* *}$ & 0.833 & 0.862 \\
\hline \multicolumn{7}{|l|}{ Indirect Effects } \\
\hline \multicolumn{7}{|l|}{ Step 1} \\
\hline Control variables & & & & 0.026 & & \\
\hline \multicolumn{7}{|l|}{ Step 2} \\
\hline Intention to use tech & & & & $0.729 * *$ & 0.885 & 0.884 \\
\hline \multicolumn{7}{|l|}{ Step 3} \\
\hline Usefulness of tech & & & & $0.309^{* *}$ & 0.894 & 0.891 \\
\hline \multicolumn{7}{|l|}{ Step 4} \\
\hline Ease of use & & & & 0.309 & 0.894 & 0.891 \\
\hline
\end{tabular}

$N=11, p<.05^{*}, p<.01^{* *}, p<.001^{* * *}$

TU that shows result $(\mathrm{B}=3.09, \mathrm{p}<.01)$ for hypothesis $5, \mathrm{EU}$ and IUT are regressed that shows result $(\mathrm{B}=$ $1.043, \mathrm{p}<.01)$.

\section{Discussion}

The study results show that there is significant and positive relation between perceived usefulness of technology and technology usage. It can be said that hypothesis 1 has been approved after statistical analysis. It is also supported by other studies for example, the usefulness of technology through which it influence the technology usage, like e-tourism is getting famous, leading to increase in technology usage (Ukpabi and Karjaluoto, 2016). The unified theory of acceptance has been used widely in the area of information technology to insure the acceptance of technology usage in different areas (Venkatesh et al., 2016).

Hypothesis 2 results are also significant and show positive relation between Ease of Use and Technology usage. It has also been proven by other researchers and statistical analysis that is performed in this study.
A study has been conducted to see how banks and financial service providers are delivering their finances through e-banking, because of the ease of use of information technology (Wang et al., 2017). Similarly, Padilla-MeléNdez et al. (2013) tried to study the behavior of students that why the trend of using information technology increase, what are the main reasons for the increase in usage.

Results for hypothesis 3 showed significant and positive relation between Intention to use technology and Technology usage. It has also substantiated by other researchers but also by statistical analysis of the study. Importance of information technology has been studied previously when you are at the journey and the people intentionally use information technology in order to remain in touch with the world (Wang et al., 2017), therefore, supporting the current study results.

Hypothesis 4 showed the positive relation between perceived usefulness of technology and Intention to use technology. The success or failure of an organization or a project depends on the effective use of technology. There is a constant interaction between employees 
and technology to make their work more effective and ideal. Leaders create cultural development mechanism and within the boundaries of the culture. Literature tells us the advantage of acceptance of wireless internet via information technology and how it is easy to use information systems (Lu et al., 2003). Likewise, the theoretical extension of technology acceptance model and intention to use technology has been researched, in order to check the social influence and instrumental process (Venkatesh and Davis, 2000).

Hypothesis 5 results showed the positive relation between Ease of use and Intention to use technology. These results are substantiated by previous studies, which tell us that why there is still limitations in applying the wide range of analysis in human neurosciences, because there is less ease of use in using information technology (Gorgolewski et al., 2017). Literature posits why there is a need to increase the ease of use of information technology so that massive open online courses will be able to help and teach a lot of students in those areas who cant afford study in expensive universities (Wu and Chen, 2017).

\subsection{Conclusion \& Implication}

After the analysis and literature support, it can be said that perceived usefulness of technology and ease of use have a positive effect on technology usage with the presence of mediating role of Intention to use technology. The current study also has theoretical and practical implication in the context of Pakistani organizations and projects. From theoretical perspective, perceived usefulness of technology and ease of use do matter for any achievement or success, if organizations ensure the technology usage. Moreover, Intention to use technology also affects the technology usage in an organization, so it can be said that perceived usefulness of technology and ease of use can help achieve technology usage with the mediating role Intention to use technology. From practical perspective of implication, here in Pakistan, project management is an emerging field of study. Now projects are planned, executed, monitored, evaluated according to the project management iron triangle. As it is said in theoretical implication that this study has significance in major portions of world so it can be said that this study is also significant in the context of Pakistan.

\subsection{Limitations \& Future Directions}

The current study has been conducted in the context of Pakistan, especially in government sector of Islamabad region. For future studies, it is suggested that this study should be conducting in other regions of Pakistan and results might be different for private sector. The other constraint was sample size that can be increased for future studies. Moreover, other variables can also be tested for the effect on technology usage in the context of Pakistan.

\section{References}

Al-Qeisi, K., Dennis, C., Alamanos, E., and Jayawardhena, C. (2014). Website design quality and usage behavior: Unified theory of acceptance and use of technology. Journal of Business Research, 67(11):2282-2290.

Bagozzi, R. P., Davis, F. D., and Warshaw, P. R. (1992). Development and test of a theory of technological learning and usage. Human relations, 45(7):659-686.

Baron, R. M. and Kenny, D. A. (1986). The moderatormediator variable distinction in social psychological research: Conceptual, strategic, and statistical considerations. Journal of personality and social psychology, 51(6):1173.

Brown, S. A., Dennis, A. R., and Venkatesh, V. (2010). Predicting collaboration technology use: Integrating technology adoption and collaboration research. Journal of Management Information Systems, 27(2):9-54.

Cai, Z., Fan, X., and Du, J. (2017). Gender and attitudes toward technology use: A meta-analysis. Computers $\mathcal{E}$ Education, 105:1-13.

Cheung, R. and Vogel, D. (2013). Predicting user acceptance of collaborative technologies: An extension of the technology acceptance model for e-learning. Computers $\mathcal{E}$ Education, 63:160-175.

Chin, W. W., Johnson, N., and Schwarz, A. (2008). A fast form approach to measuring technology acceptance and other constructs. MIS Quarterly, pages 687-703.

Costa, C. J., Ferreira, E., Bento, F., and Aparicio, M. (2016). Enterprise resource planning adoption and satisfaction determinants. Computers in Human Behavior, 63:659-671.

Gallivan, M. J., Spitler, V. K., and Koufaris, M. (2005). Does information technology training really matter? a social information processing analysis of coworkers' influence on it usage in the workplace. Journal of Management Information Systems, 22(1):153-192.

Gorgolewski, K., Esteban, O., Schaefer, G., Wandell, B., and Poldrack, R. (2017). Openneuroa free online platform for sharing and analysis of neuroimaging data. Organization for Human Brain Mapping. Vancouver, Canada, page 1677.

Hallikainen, H., Paesbrugghe, B., Laukkanen, T., Rangarajan, D., and Gabrielsson, M. (2017). How individual technology propensities and organizational culture influence $b 2 b$ customers behavioral intention to use digital services at work? In Proceedings of the 50th Hawaii International Conference on System Sciences.

Howard, R., Restrepo, L., and Chang, C.-Y. (2017). Addressing individual perceptions: An application of the unified theory of acceptance and use of technology to building information modelling. International Journal of Project Management, 35(2):107-120. 
Hwang, Y., Chung, J.-Y., Shin, D.-H., and Lee, Y. (2017). An empirical study on the integrative pre-implementation model of technology acceptance in a mandatory environment. Behaviour E Information Technology, pages 1-14.

ICHIKOHJI, T. (2016). Technology adoption: Influence of personal attributes and person-organization adaptation. Organizational Science, 48(5):33-48.

Järvinen, J., Ohtonen, R., and Karjaluoto, H. (2016). Consumer acceptance and use of instagram. In System Sciences (HICSS), 2016 49th Hawaii International Conference on, pages 2227-2236. IEEE.

Kwon, O., Lee, N., and Shin, B. (2014). Data quality management, data usage experience and acquisition intention of big data analytics. International Journal of Information Management, 34(3):387-394.

Legris, P., Ingham, J., and Collerette, P. (2003). Why do people use information technology? a critical review of the technology acceptance model. Information $\mathcal{E}$ management, 40(3):191-204.

Lu, J., Lu, C., Yu, C.-S., and Yao, J. E. (2003). Exploring factors associated with wireless internet via mobile technology acceptance in mainland china. Communications of the IIMA, 3(1):9.

Malhotra, Y. and Galletta, D. (2005). A multidimensional commitment model of volitional systems adoption and usage behavior. Journal of Management Information Systems, 22(1):117-151.

Mayer, R. C., Davis, J. H., and Schoorman, F. D. (1995). An integrative model of organizational trust. Academy of management review, 20(3):709-734.

Ouyang, Y., Schlub, R. W., Jin, N., and Pascolini, M. (2017). Shared antenna structures for near-field communications and non-near-field communications circuitry. US Patent $9,793,616$.

Padilla-MeléNdez, A., Del Aguila-Obra, A. R., and GarridoMoreno, A. (2013). Perceived playfulness, gender differences and technology acceptance model in a blended learning scenario. Computers $\mathcal{E}$ Education, 63:306-317.
Rojas-Méndez, J. I., Rojas-Méndez, J. I., Parasuraman, A., Parasuraman, A., Papadopoulos, N., and Papadopoulos, N. (2017). Demographics, attitudes, and technology readiness: A cross-cultural analysis and model validation. Marketing Intelligence $\mathcal{E}$ Planning, 35(1):18-39.

Toft, M. B., Schuitema, G., and Thøgersen, J. (2014). Responsible technology acceptance: Model development and application to consumer acceptance of smart grid technology. Applied Energy, 134:392-400.

Ukpabi, D. C. and Karjaluoto, H. (2016). Consumers acceptance of information and communications technology in tourism: A review. Telematics and Informatics.

Venkatesh, V. and Davis, F. D. (2000). A theoretical extension of the technology acceptance model: Four longitudinal field studies. Management science, 46(2):186-204.

Venkatesh, V., Thong, J. Y., and Xu, X. (2016). Unified theory of acceptance and use of technology: a synthesis and the road ahead.

Wallace, L. G. and Sheetz, S. D. (2014). The adoption of software measures: A technology acceptance model (tam) perspective. Information \& Management, 51(2):249-259.

Wang, M., Wang, M., Cho, S., Cho, S., Denton, T., and Denton, T. (2017). The impact of personalization and compatibility with past experience on e-banking usage. International Journal of Bank Marketing, 35(1):45-55.

Wouters, E. J., Weijers, T. C., and Nieboer, M. E. (2017). Professional values: The use of technology and the new generation of clinicians. Handbook of Smart Homes, Health Care and Well-Being, pages 147-154.

Wu, B. and Chen, X. (2017). Continuance intention to use moocs: Integrating the technology acceptance model (tam) and task technology fit (ttf) model. Computers in Human Behavior, 67:221-232.

Zheng, Y. (2016). Toward A Situational Technology Acceptance Model: Combining the Situational Theory of Problem Solving and Technology Acceptance Model to Promote Mobile Donations for Nonprofit Organizations. PhD thesis, University of South Carolina. 